\title{
APPLIANCES
}

\section{A NEW TYPE OF EYE ENDOSCOPE*}

\author{
BY \\ ROBERT F. BUTTERWORTH AND JOHN L. BIGNELL \\ Departments of Physiology and Pathology, University of Melbourne, Australia
}

OUR knowledge of the interior of the eye has been greatly advanced by the use of the ophthalmoscope, slit lamp, and gonioscope, but the region about and forward from the ora serrata remains invisible. Therefore the nature of any pathological process must be deduced indirectly from its effect on the lens, vitreous, and retina, or by transillumination. A new endoscope has therefore been devised which utilizes the unique light-transmitting properties of solid Perspex (methyl methacrylate). With it this previously almost unknown territory can be inspected; whilst the addition of a small forceps enables any type of foreign body within the globe to be rapidly located and removed with a minimum of trauma.

\section{Advantages}

The instrument (Fig. 1), which can be made within a few hours by any precision toolmaker, has the following important advantages over previous types of apparatus:

(1) Simplicity: the entire instrument, apart from the operating forceps and light source, is made from solid Perspex.

(2) Lightness: the weight of the complete instrument is only half an ounce.

(3) The visual field extends to the extreme edge of the instrument without obstruction by light bulb or metal case. The actual operating shaft therefore need not be more than $2.5 \mathrm{~mm}$. in diameter.

(4) Polished Perspex is easily sterilized, it does not transmit heat and its inert water-repellant surface is ideal

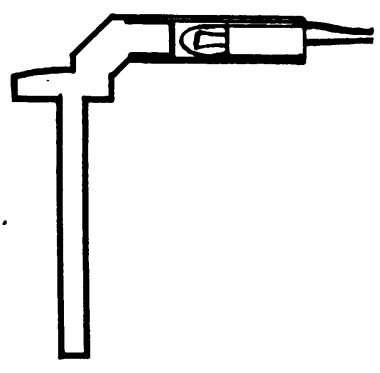

Fig. 1.-Arrangement of light source. for contact with delicate tissues. 


\section{CONSTRUCTION}

The instrument consists essentially of a solid Perspex viewing and illuminating shaft down which a strong parallel beam of light is projected. Light rays must be parallel to provide for illumination at a distance. The upper end is ground to a convex lens surface of approximately $35 \mathrm{~mm}$. focal length, so that the operator's eye may be brought close to the instrument and a magnified field obtained.

The methods of illumination so far used have depended on the right-angled reflection of light in a prism, one half of the shaft being used for illuminating, and the other for viewing. Three types of instrument are shown (Fig. 2).

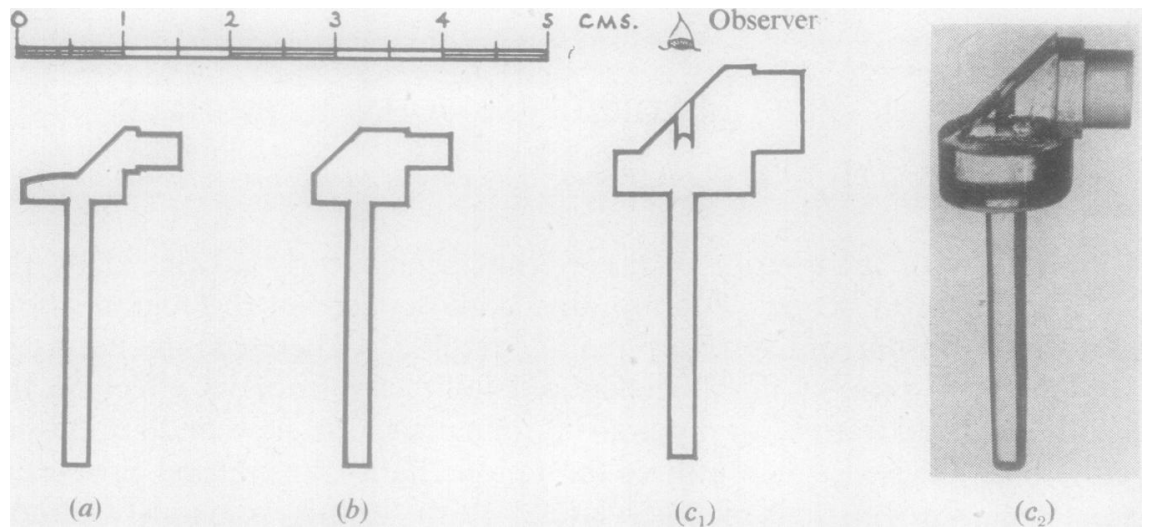

FIG. 2.-Three types of endoscope ( $c_{2}$ is a photograph of $c_{1}$ ).

The single-jawed operating instrument (Fig. 3) is slim and very satisfactory for foreign bodies actually in the vitreous. For those embedded in the retina or ciliary body, sideways-closing forceps are being developed to grasp the projecting portion.

The shaft and prism are made separately and cemented together with liquid

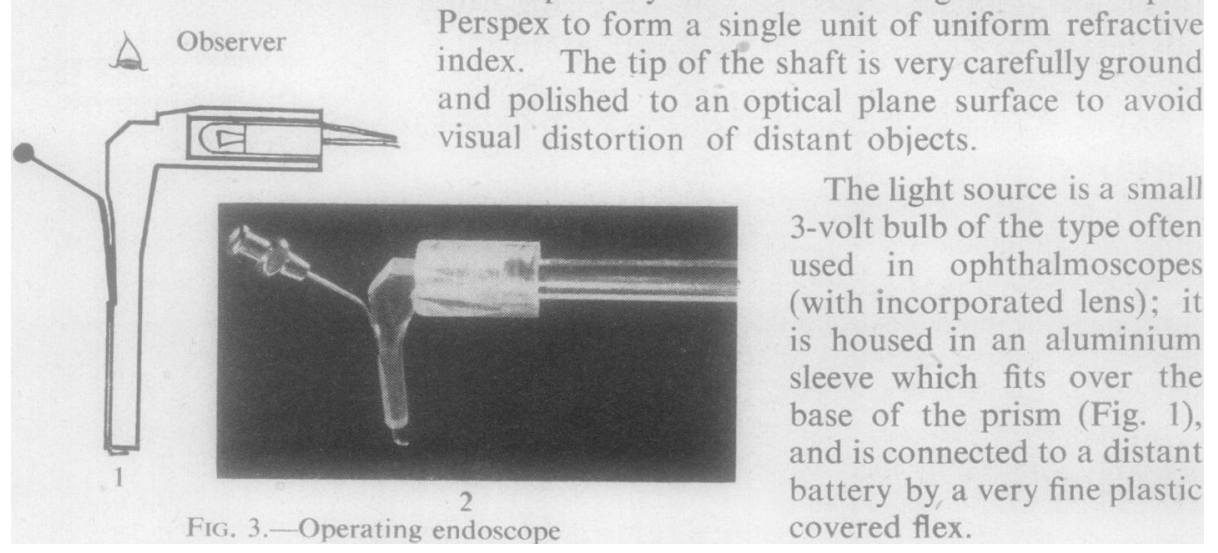




\section{Method OF UsE}

Experiments have been made both on the living dog and on the human cadaver. The sclera is laid bare $8-10 \mathrm{~mm}$. from the limbus at a position opposite the region to be inspected, or the presumed site of the intra-ocular foreign body, and the eye fixed into position with sutures to the episcleral tissues, or to the tendons of the recti muscles. A small incision is made down to the uveal tissue with a knife or sharp needle, and a cyclodialysis spatula inserted to separate the uvea from the sclera. The incision is then lengthened in a meridional direction to form a hole large enough to admit the tip of the endoscope.

Alternatively, a U-shaped incision may be made. This is easier both to manage during insertion of the instrument, and also to suture.

The intra-ocular pressure, if not sufficiently low, is now reduced by paracentesis of the anterior chamber.

A hole is then made in the pars plana of the ciliary body with a punctum dilator, the point of which is directed somewhat backwards, and the opening thus formed is enlarged by scissors which are inserted closed and opened meridionally. The vitreous presents at the opening but does not escape if the intra-ocular pressure has been sufficiently reduced. The instrument is then placed on this vitreous surface just inside the globe, and a search made of the vitreous and internal structures of the globe under direct vision. More detailed inspection can be made by advancing the instrument across the vitreous to within 1 or $2 \mathrm{~mm}$. of the area under review. Having been detected, the foreign body is grasped with the forceps and withdrawn along with the instrument. The sclera is then closed with previously inserted silk sutures and the conjunctiva repaired.

In dogs, various types of experimentally inserted foreign bodies, often outside the range of ophthalmoscopic vision, have been recovered easily and rapidly. Even very small brass, steel, or aluminium fragments show up brilliantly immediately the instrument is inserted. Small pieces of glass present greater difficulty but can be picked out by the diffraction of light at the broken edges.

A very clear view is obtained of the optic disk, retinal vessels, and ora serrata. The ciliary processes are less clearly seen because of their blackness and the small amount of light reflected, but otherwise the ciliary body shows plainly. No apparent damage is done to the eye. Ophthalmoscopically the track of the instrument can sometimes be detected in the vitreous but no other changes are seen. The retinal vessels were compressed with the tip of the instrument on several occasions without harm, but repeated stroking movements caused bleeding from the choroidal vessels.

The interior of the human eye in the cadaver was inspected and parts not previously seen during life were brought into view. 


\section{Discussion}

This instrument will help to extend our knowledge of the pathology of the interior of the eye. It should be especially useful in the differential diagnosis of a suspected melanoma situated far forward.

Non-magnetic foreign bodies in the eye have always been a most difficult problem, and Savin (1948) suggests that a high percentage of affected eyes are ultimately lost. Expeditious removal of foreign bodies under direct vision now appears practicable, without the need for the more elaborate methods of $x$-ray localization, and with much less risk of missing very small or non-opaque particles operatively.

Further experimental work is proceeding, and the instrument is now ready to be tried out on the living human eye as soon as a suitable case presents.

\section{SUMMARY}

(1) Our comparative ignorance of the living pathology of the forward part of the posterior eye is discussed, and a new endoscope for viewing this region is described.

(2) The construction of the instrument is described, and its advantages over previous types enumerated.

(3) The results of cadaver and animal experiments are recorded.

(4) The value of this new instrument in differential diagnosis and in the removal of foreign' bodies is discussed.

We wish to acknowledge the constant help and encouragement given. by Professor R. D. Wright, Professor of Physiology, and Professor E. S. J. King, Professor of Pathology, in the University of Melbourne. Experimental facilities were provided by Professor Wright in the Physiology Department.

\section{REFERENCE}

SAvin, L. H. (1948). In "Modern Trends in Ophthalmology", ed. A. Sorsby, vol. 2., p. 469. Butterworth, London. 